\title{
ARTIGOS
}

Submetido 10.05.2016. Aprovado 04.04.2017

Avaliado pelo processo de double blind review. Editor científico: Paulo B. Tigre

DOI: http://dx.doi.org/10.1590/So034-759020170404

\section{CONFIANÇA NOS RELACIONAMENTOS EM CLUSTER DE EMPRESAS}

\author{
Trust in relationships in business clusters \\ Confianza en las relaciones en clusters de empresas
}

\begin{abstract}
RESUMO
Este estudo propõe integrar os relacionamentos interorganizacionais (verticais e horizontais) por meio da percepção da confiança no comportamento colaborativo das empresas. Serão utilizados como campo empírico clusters produtivos da indústria moveleira brasileira, localizados em Arapongas, Mirassol, Ubá e Bento Gonçalves. Os dados foram coletados por meio de questionários in loco e analisados pelas técnicas estatísticas de análise de correlação e teste de causalidade de Granger. A confiança foi analisada na dimensão benevolência e a sua relação com o comprometimento. Os resultados demonstraram que há causalidade no relacionamento horizontal e que não há causalidade nos relacionamentos entre fornecedores e clientes, tampouco nos relacionamentos entre estes e os concorrentes. Contudo, há uma forte correlação entre a confiança nos clientes e os relacionamentos horizontais. Assim, ficou constatado que a presença da confiança nas relações interorganizacionais é independente e isolada, não se caracterizando como uma atitude permanente e rotineira.
\end{abstract}

PALAVRAS-CHAVE | Rede de suprimentos, confiança, relacionamentos interorganizacionais, indústria moveleira, clusters produtivos.

ROBERTA DE CÁSSIA MACEDO

roberta.c.macedo@gmail.com

Doutoranda em Administração

de Empresas pela Universidade

Federal de Minas Gerais,

Faculdade de Ciências

Econômicas - Belo Horizonte -

MG, Brasil

\section{RICARDO SILVEIRA MARTINS}

ricardomartins.ufmg@gmail.com Professor da Universidade

Federal de Minas Gerais,

Faculdade de Ciências

Econômicas - Belo Horizonte -

MG, Brasil

\section{LUCIANO ROSSONI}

Irossoni@gmail.com

Professor da Universidade do

Grande Rio, Programa de Pós-

Graduação em Administração -

Rio de Janeiro - RJ, Brasil

\section{GUILHERME SILVEIRA MARTINS}

guilhermesm2@insper.edu.br

Professor do Instituto de Ensino

e Pesquisa - São Paulo - SP,

Brasil

\section{ABSTRACT}

This study aims to integrate interorganizational relationships (both vertical and horizontal ones) through the perception of trust in businesses' collaborative behavior. We will use as our empirical field the Brazilian furniture industry production clusters situated in the cities of Arapongas, Mirassol, Ubá and Bento Gonçalves. Data were collected through questionnaires which were administered in loco and analyzed using correlation analysis and the Granger causality test. Trust was analyzed in the benevolence dimension and its relationship with commitment. Results demonstrated that there is causality in the horizontal relationship and that there is no causality in relationships between suppliers and clients, nor in relationships between those and competitors. However, there is a strong correlation between trust in clients and horizontal relationships. Therefore, it was verified that the presence of trust in interorganizational relationships is independent and isolated, and not a permanent, routine attitude.

KEYWORDS / Supply network, trust, interorganizational relationships, furniture industry, production clusters.

\section{RESUMEN}

Este estudio propone la integración de las relaciones interorganizacionales (verticales y horizontales) a través de la percepción de confianza en el comportamiento de colaboración de las empresas. Como campo empírico se utilizaron clusters productivos de la industria de muebles brasileña, localizados en Arapongas, Mirassol, Ubá y Bento Gonçalves. Los datos se recolectaron a través de cuestionarios en campo y se analizaron mediante técnicas estadísticas de análisis de correlación y prueba de causalidad de Granger. Se examinó la confianza en la dimensión benevolencia y su relación con el compromiso. Los resultados mostraron que existe causalidad en la relación horizontal pero no entre proveedores y clientes, y tampoco en las relaciones entre estos y sus competidores. Sin embargo, hay una fuerte correlación entre la confianza en los clientes y las relaciones horizontales. De este modo, se ha constatado que la presencia de la confianza en las relaciones interorganizacionales es independiente y aislada y no se caracteriza como una actitud permanente y cotidiana.

PALABRAS CLAVE / Red de abastecimiento, confianza, relaciones interorganizacionales, industria de muebles, clusters productivos. 


\section{INTRODUÇÃO}

As explicações das vantagens competitivas por meio dos relacionamentos têm diversas fontes teóricas, como a Teoria das Redes e do Capital Social, que partiram do arcabouço da visão relacional desenvolvida por Dyer e Singh (1998). Adicionalmente, a literatura das áreas do marketing de relacionamento e de rede de suprimentos têm proporcionado mais evidências nos relacionamentos verticais (aqueles formados com fornecedores e clientes), e a abordagem principal é dada aos benefícios da colaboração com os fornecedores. Já no campo da geografia econômica, se encontram subsídios suficientes para entender os potenciais benefícios em colaborar nos relacionamentos horizontais (atitudes cooperativas com concorrentes e agentes governamentais, por exemplo), especialmente quando estes se localizam no mesmo espaço geográfico (Nicholson, Tsagdis, \& Brennan, 2013). Sob qualquer lente teórica, os relacionamentos interorganizacionais podem ser fontes de valor para as redes de suprimentos.

Para Kumar, Banerjee, Meena, e Anguly (2016), os relacionamentos interorganizacionais são fontes competitivas relevantes indubitáveis, e suas constatações apontaram para o papel do construto confiança presente no relacionamento. 0 nível de aprofundamento no relacionamento resulta de escolhas estratégicas, tendo em mente o objetivo de alavancar e manter as vantagens competitivas das empresas (Rossoni, Martins, Martins, \& Silveira, 2014).

Este estudo pretende investigar evidências da existência da propensão à colaboração das empresas em seus relacionamentos interorganizacionais. Para tal, será considerada a dimensão confiança, tanto no âmbito dos relacionamentos horizontais quanto no âmbito dos relacionamentos verticais. Assim, propõe-se integrar as vertentes do marketing industrial e da geografia econômica para melhor compreender a relação entre o nível de aprofundamento dos relacionamentos em caso de aglomeração de empresas. Essa integração é potencialmente promissora e foi lançada como um desafio no estudo seminal de Halinen e Tornroos (1998), que chamaram a atenção dos estudiosos de marketing industrial para a necessidade da melhor compreensão da imersão espacial e seus efeitos nos relacionamentos interoganizacionais (Business to Business) e na performance empresarial. Para Cantù (2010), foi um desafio pouco enfrentado pela academia, mas, talvez, mais desenvolvido pelas políticas públicas e agências governamentais.

Assim, a propensão a colaborar nas empresas foi tratada neste estudo a partir da avaliação da dimensão confiança nas relações interorganizacionais. Dessa forma, a questão que esta pesquisa pretendeu tratar foi formulada da seguinte maneira: A confiança, como um atributo do relacionamento, configura-se um elemento da estratégia comercial ou pode ser entendida como uma atitude colaborativa da empresa? De maneira mais pragmática, o propósito foi avaliar se as empresas que confiam em seus clientes e fornecedores (relacionamentos verticais) também confiam em seus concorrentes (relacionamentos horizontais). 0 campo empírico deste estudo foi a indústria moveleira brasileira, em clusters produtivos.

0 artigo, além desta seção introdutória, está organizado da seguinte forma: a próxima seção discute as abordagens teóricas, enquanto a terceira seção descreve a metodologia. Os resultados obtidos são apresentados e discutidos na quarta seção, enquanto na última seção são feitas as considerações finais.

\section{REFERENCIAL TEÓRICO}

Os relacionamentos são abordados neste estudo em suas relações interorganizacionais verticais e horizontais, com interesse no construto confiança. Para tal, foram utilizados aportes conceituais e teóricos advindos da visão relacional e preceitos da Teoria do Capital Social e da Teoria das Redes.

Os processos logísticos interorganizacionais são as bases das redes de suprimentos (Lambert \& Einz, 2016) e estão associados ao agrupamento de empresas (a montante e a jusante) que buscam trabalhar conjuntamente, colaborando e criando valor único e de difícil imitação (Braziots \& Tannock, 2011). Essa integração dos participantes de uma rede de suprimentos desloca as organizações de uma visão intrafuncional e as direciona a uma visão interorganizacional, configurando esse cenário como uma estratégia de enfrentamento da intensificação da competição (Ballou, Gilbert, \& Murkherjee, 2000).

Os relacionamentos são a base para a compreensão da integração interorganizacional nas redes de suprimentos. Dyer e Singh (1998) afirmam que um elemento cada vez mais forte para analisar e compreender a vantagem competitiva está no relacionamento entre as empresas. $E$, em último plano, a eficácia dos relacionamentos nesse papel é definida pelo nível de colaboração. Conforme Simatupang e Sridharan (2002), a colaboração na rede de suprimentos é representada por dois ou mais membros da rede trabalhando em conjunto para criar vantagem competitiva por meio de decisões conjuntas, compartilhamento de informações e consequentes benefícios.

A intenção ao acentuar a colaboração na rede de suprimentos é promover vínculos relacionais que levarão à repetição de negócios confiáveis (Daugherty, 2011). Para os 
seguidores da visão relacional, tais vínculos relacionais, quando fortalecidos pela empresa, podem representar uma base para a vantagem competitiva (Braziots \& Tannock, 2011). Nesse contexto, a vantagem competitiva das empresas está respaldada nos frequentes e múltiplos relacionamentos colaborativos com os parceiros da rede de suprimentos. Assim, este artigo defende que a avaliação da empresa passa a ser fundamentada não apenas nos seus recursos e competências internas, mas também pelos recursos de seus parceiros (Lavie, 2006).

A abordagem relacional como vantagem competitiva é fortalecida pelo conceito de valor transacional, desenvolvido por Zajac e Olsen (1993). Esses autores preconizam que a estratégia das empresas deve enfatizar a maximização dos valores gerados pelo relacionamento em vez de se empenharem em combater o comportamento oportunista e o custo de transação. A perspectiva do valor transacional é dominada pela hipótese de que o impacto negativo de um comportamento oportunista pode ocasionar perdas futuras de negócios. Contudo, o valor transacional gerado pelo relacionamento da troca e pela interdependência das empresas é o fator inibidor do comportamento oportunista e do custo de transação. Este artigo considera o comportamento oportunista uma estratégia comercial da empresa em que a relação entre as partes está despida de qualquer valor transacional ou relacional.

O relacionamento entre empresas é possível quando os parceiros combinam, trocam e investem em ativos específicos e dedicados, conhecimentos, recursos e capacitações, além de empregar eficazes mecanismos de governança. A presença e aplicação da governança implicam diminuição da prática de oportunismo nas relações comerciais (Dyer \& Singh, 1998).

Para Slack, Chambers, e Johnston (2009), a disposição de um ente para se relacionar com o outro está associada à presença de um elemento-chave dessa parceria: a confiança. Ademais, parte-se do pressuposto de que esse relacionamento é benéfico às duas partes (mesmo que não haja garantias). A confiança é um construto multidimensional e é uma vontade decorrente de quatro aspectos: (1) a crença na boa intenção e na preocupação dos parceiros de troca, (2) a crença em sua competência e capacidade, (3) a crença na sua credibilidade, e (4) a crença em sua abertura percebida (mente aberta) (Nahapiet \& Ghoshal, 1998).

Mayer, Davis, e Schoorman (1995) explicam a confiança organizacional envolvendo dois lados: a parte que confia (trustor) e a parte que recebe a confiança (trustee). Assim, a confiança é recíproca ou relacional e pode ser baseada na rede. Ela é relacional porque possui uma orientação social, resultando em contratos relacionais que incluem expectativas, normas e também um longo horizonte de trocas. Quando baseada em uma densa rede de relações, pode facilitar a propagação da reputação de uma empresa (Zaheer \& Harris, 2006). Nesse sentido, ao tratar a confiança nos relacionamentos, este artigo busca compreender se a sua existência está pautada em ações isoladas e com interesses específicos ou se há atitudes colaborativas intrincadas nas relações da empresa. Este artigo considera as atitudes colaborativas a propensão à colaboração a partir da presença do atributo confiança nos relacionamentos verticais e horizontais.

Os relacionamentos colaborativos baseados na confiança são geradores de diferenciais e formam o capital social. Adler e Kwon (2000) afirmam que a amplitude do conceito de capital social reflete uma característica da vida social: os laços sociais (como amizade) que podem ser usados para diferentes propósitos. O capital social, então, é um recurso disponível para os integrantes de laços sociais. A intensidade desse recurso dá-se em função da localização do ator na estrutura de suas relações sociais. 0 capital social resulta em benefícios, tais como melhores acessos às informações, poder e solidariedade. Assim, a Teoria do Capital Social acredita que os laços sociais constituem recursos valiosos e que são alcançados em virtude da relação social do indivíduo (Lesser, 2000; Nahapiet, 2008).

Os economistas não reconhecem as conexões relacionais dos atores e tendem a adotar uma visão sub ou supersocializada do comportamento econômico. Para Granovetter (2007), na abordagem subsocializada, buscam-se os interesses próprios, e, na supersocializada, emana a ideia em que há a interiorização de padrões comportamentais. Consequentemente, as relações sociais exercem efeitos marginais, e não centrais, sobre o comportamento dos atores. Em contraste à visão supersocializada, o próprio Granovetter (2007) propôs a noção de enraizamento social. 0 enraizamento social ocorre quando, a partir de motivos puramente econômicos, as relações se tornam frequentes e com conteúdo social. Portanto, é possível sustentar que as relações de negócios se misturam com as relações sociais. Tais relações possuem fortes expectativas de confiança e ausência de oportunismo (Bachmann \& Zaheer, 2008).

Para Lin (2001), o capital social conceitua-se como o investimento em relações sociais com expectativa de retorno no mercado. Assim, indivíduos se engajam em interações e networking para produzir o superávit. Burt (2001) acredita que o capital social é um complemento contextual do capital humano, pois a pessoa que faz melhor de alguma maneira está mais bem conectada. Melhores conexões fazem as pessoas desfrutar de retornos elevados.

Pesquisadores da Teoria das Redes Sociais argumentam que a compreensão do capital social exige uma análise refinada das estruturas específicas da rede que está sendo avaliada. Esses mesmos teóricos afirmam que as redes sociais influenciam o 
capital social de um ator focal pelos laços diretos e indiretos. Essa influência ocorre em virtude da estrutura global da rede dentro da qual estão inseridos (Adler \& Kwon, 2000).

Burt (2001) argumenta que uma rede dispersa, com poucos laços redundantes, muitas vezes proporciona maiores benefícios ao capital social. Para esse autor, a oportunidade de intermediar o fluxo de informações entre grupos constitui um benefício fundamental para o capital social, considerando-se buracos estruturais, que são ligações a grupos que, de outra forma, não estariam conectados.

\section{Variáveis do modelo}

As variáveis consideradas neste artigo são confiança nos clientes e confiança nos fornecedores para os relacionamentos verticais, e benevolência nos polos e o comprometimento nos polos para os relacionamentos horizontais.

A colaboração é comumente diferenciada em termos de sua estrutura, como colaboração vertical, colaboração horizontal e colaboração lateral (Badea, Prostean, Goncalves, \& Allaoui, 2014; Mason, Lalwani, \& Boughton, 2007). Os relacionamentos verticais são aqueles que ocorrem entre organizações que desenvolvem atividades complementares (fornecedor, cliente) e compartilham responsabilidades, recursos e informação de performance para atender o cliente final (Simatupang \& Sridharan, 2002). Já os relacionamentos horizontais ocorrem quando duas ou mais organizações não relacionadas ou concorrentes cooperam para partilhar informações ou recursos particulares. Esse tipo de colaboração pode ocorrer entre organizações que estão em clusters produtivos, que são do mesmo porte, que trabalham em um mesmo segmento, e pode envolver instituições que ofereçam suporte à atividade empresarial (associações empresariais, sindicatos, entre outros) (Badea et al., 2014; Mason et al., 2007; Simatupang \& Sridharan, 2002).

Ao tratar de relacionamentos, o elemento confiança se destaca por sua função na criação de valor. Conceitualmente, confiança é um fenômeno que ocorre no âmbito do indivíduo (Dyer \& Chu, 2003). Ou seja, a confiança é um atributo possível às organizações, mas que ocorre a partir da ação do indivíduo. Então, a confiança pode ser considerada um elemento importante e interveniente no relacionamento, porque a confiança, como fator essencial para a manutenção de relacionamentos, configura-se fenômeno autogerativo. Isto é, tanto a confiança quanto a desconfiança estão propensas a serem reforçadas pelas experiências positivas ou negativas.

Neste artigo, adota-se a definição de confiança utilizada por Lado, Dant, e Tekleab (2008), em que a confiança é a boa vontade (benevolência) do parceiro na troca relacional. Em complemento, a definição de benevolência teve como base Mayer et al. (1995). Para esses autores, a benevolência ocorre quando o trustee quer trazer benefícios para o trustor, e não apenas a obtenção do seu lucro. A benevolência é uma percepção da orientação positiva e verdadeira do trustee para o trustor e pode ser vista como a base da confiança.

A confiança é um atributo de uma relação de troca, em vez de um atributo de um determinado ente da troca relacional. Considerando a confiança um fator do relacionamento, presume-se que a troca relacional (e não a transacional) traz intricada uma visão de relacionamentos de longo prazo. Entre os elementos motivadores do relacionamento de longo prazo entre empresas, Redondo e Fierro (2007) indicaram a confiança e o comprometimento como fatores de grande impacto. Lado et al. (2008) preconizam que, em relacionamentos baseados em altos níveis de confiança, as partes envolvidas podem identificar e desenvolver laços mais fortes umas com as outras, o que resulta em um maior nível de comprometimento com a relação de troca.

Já a definição de comprometimento foi embasada em Morgan e Hunt (1994). Para esses autores, o comprometimento é definido como um desejo duradouro de manter um relacionamento valorizado, em que relacionamento valorizado parte do pressuposto de que o comprometimento existe apenas quando se considera o relacionamento importante e "um desejo duradouro de manter" corresponde ao compromisso dos parceiros de desejarem dar suporte à relação indefinidamente e estarem dispostos a trabalhar por ela. Esses autores também definem o comprometimento e a confiança como fatores centrais para o sucesso do relacionamento: i) trabalho para preservar os investimentos na relação de cooperação com os parceiros de troca, ii) resistência aa alternativas atraentes de curto prazo em favor dos benefícios a longo prazo, e iii) crença de que os seus parceiros não agirão de maneira oportunista.

Os relacionamentos pautados em confiança são tão valorizados que despertam o desejo das partes de se comprometerem na relação. A confiança é o maior determinante do compromisso nos relacionamentos. Conjuntamente, comprometimento e confiança incentivam as empresas a preservarem seus relacionamentos e investirem na cooperação, priorizam negociações de longo prazo em detrimento das negociações de curto prazo e, com isso, acreditam que o parceiro não agirá de maneira oportunista. A presença desses dois construtos (confiança e comprometimento) na relação gera resultados que estimulam a eficiência, a produtividade e a eficácia, ou seja, conduzem as empresas a comportamentos cooperativos (Morgan \& Hunt, 1994). 


\section{PROCEDIMENTOS METODOLÓGICOS}

Esta pesquisa caracteriza-se como aplicada e descritiva, uma vez que utiliza arcabouços já elaborados e se propõe a estudar e descrever o vínculo do construto confiança nas relações verticais e horizontais de quatro polos moveleiros, por meio da análise de correlação e causalidade de Granger.

A unidade de análise da pesquisa foi a percepção da empresa fabricante de móveis de madeira acerca do comportamento de seus clientes, fornecedores e concorrentes tomados em conjunto. Já as unidades de observação foram as empresas fabricantes de móveis de madeira localizadas nos clusters produtivos de Arapongas (PR), Mirassol (SP), Ubá (MG) e Bento Gonçalves (RS). Ainda que existam empresas produtoras de móveis em todas as regiões do País, há concentração nas regiões Sul e Sudeste, com $83 \%$ do total de empresas e dos empregos formais do setor (Galinari, Teixeira, \& Morgado, 2013). Esses clusters são representativos do setor moveleiro dessas regiões.

A coleta de dados ocorreu in loco, no período de maio a setembro de 2011. A técnica utilizada no levantamento de dados foi o questionário, e a maioria dos respondentes foram os gestores das empresas fabricantes de móveis. Esses gestores avaliaram os relacionamentos verticais e horizontais Business to Business. A amostra foi composta por 75 empresas que fabricam móveis de madeira, sendo 20 em Arapongas, 12 em Mirassol, 23 em Ubá e 19 em Bento Gonçalves. A amostragem das empresas foi não probabilística e seguiu, principalmente, os parâmetros de conveniência e acessibilidade, por indicação de entidades locais e sindicatos patronais.

Foram apresentadas afirmativas para avaliação dos respondentes em escala Likert de seis pontos. A escala Likert com o número par de opções foi escolhida porque assim se elimina o "ponto do meio" nos questionários. Há evidências de que alguns indivíduos que optam por pontuações neutras em escalas de avaliação não se consideram necessariamente neutros em relação ao objeto avaliado (Matell \& Jacoby, 1972). Um número par pode ser um facilitador para uma posição mais confortável para os respondentes que não estão dispostos a expressar uma visão definida.

\section{Análise das variáveis}

As variáveis dos relacionamentos verticais consideradas nas análises foram confiança nos clientes e confiança nos fornecedores, seguindo os eixos básicos presentes em Lado et al. (2008). Os indicadores buscam avaliar o nível de confiança que as empresas moveleiras percebem de seus fornecedores e clientes.
As afirmativas avaliadas na escala Likert de seis pontos foram: "acreditamos que nossos principais clientes ou fornecedores são honestos nas suas relações conosco"; "nossos clientes ou fornecedores são reconhecidos porque honram os acordos"; "nossos clientes ou fornecedores são sinceros nas suas relações conosco"; "nossos clientes ou fornecedores sempre fazem o que é idôneo" e "temos grande confiança em nossos clientes ou fornecedores".

As variáveis dos relacionamentos horizontais consideradas nas análises foram benevolência nos polos e comprometimento nos polos, seguindo também os indicadores de Lado et al. (2008) e Mayer et al. (1995) para benevolência e nos estudos de Morgan e Hunt (1994) para comprometimento. A variável benevolência nos polos busca avaliar o nível de confiança que as empresas moveleiras depositam em seus concorrentes. As afirmativas avaliadas na escala Likert de seis pontos foram: "acreditamos que as empresas do polo são honestas nas relações e iniciativas conjuntas com as outras empresas do polo"; "acreditamos que as empresas do polo são sinceras nas relações e iniciativas conjuntas com as outras empresas do polo"; "acreditamos que as empresas do polo são idôneas nas relações e iniciativas conjuntas com as outras empresas do polo".

A variável comprometimento nos polos busca também avaliar o nível de comprometimento das empresas moveleiras com seus concorrentes. As afirmativas avaliadas na escala Likert de seis pontos foram: "acreditamos que as empresas do polo estão comprometidas nas relações e iniciativas conjuntas com as outras empresas do polo"; "acreditamos que as empresas do polo estão comprometidas com um relacionamento cooperativo com as outras empresas do polo"; "é comum entre as empresas do polo compartilhar informações sobre fornecedores, mercado e clientes" e "é comum entre as empresas do polo compartilhar informações sobre materiais, custos e novas técnicas de produção".

As variáveis foram analisadas primeiramente pelo método análise de regressão. Entretanto, constatou-se alto nível de correlação entre as variáveis explicativas dos modelos. Dessa forma, foram utilizados testes estatísticos de correlação, análise de correlação seguida da causalidade de Granger, uma vez que o objetivo do estudo era analisar a ocorrência de confiança nos relacionamentos verticais e nos relacionamentos horizontais.

\section{Análise de correlação}

A análise de correlação é desenvolvida por meio do Coeficiente de Correlação Linear de Pearson, que é uma medida padronizada de associação, de interdependência, de intercorrelação ou de relação entre variáveis. Embora a correlação linear trate da 
associação entre duas variáveis, ela não implica a existência da relação de causalidade entre elas. 0 coeficiente de correlação amostral entre duas variáveis hipotéticas $X$ e Y é denominado por r e estimado pela seguinte equação:

$$
r=\frac{\frac{1}{n} \sum_{i}\left(X_{i}-\bar{X}\right)\left(Y_{i}-\bar{Y}\right)}{S_{x} S_{y}}, 1 \leq r \leq 1
$$

em que,

$n$ é o tamanho da amostra;

$X_{i}$ e $Y_{i}$ são as i-ésimas observações das variáveis X e Y;

$X$ e $Y$ são as médias das variáveis $\mathrm{X}$ e $\mathrm{Y}$; e

$S_{x}$ e $S_{y}$ são os desvios-padrão amostrais das variáveis X e Y.

Os valores do resultado da correlação variam entre de \pm 1 . Os sinais, positivo ou negativo, indicam se as trajetórias são coincidentes ou não, e os valores indicam a intensidade de aproximação/dispersão das trajetórias das variáveis. Não obstante, não é facilmente deduzido que a correlação seja forte ou fraca, pois não há um parâmetro de comparação exato desse coeficiente. 0 nível de significância da correlação é obtido pela comparação com a estatística T-Student n-2 graus de liberdade.

\section{Teste de causalidade de Granger}

O teste de causalidade de Granger afere a causalidade entre duas variáveis. Maddala (1992) pondera que esse teste não se propõe a identificar uma relação de causalidade no seu sentido de endogeneidade. Dessa forma, dado um determinado conjunto de informações do qual fazem parte as variáveis $\mathrm{X}$ e $\mathrm{Y}$, diz-se que a variável Y Granger causa a variável X se o valor corrente de $\mathrm{X}$ pode ser predito com maior precisão quando se levam em conta valores passados de Y, em contraste com uma alternativa em que a história de Y é ignorada. Os modelos são representados pelas seguintes equações:

$$
X_{t}=a+\sum_{i=1}^{m} b_{i} X_{t-1}+\sum_{i=1}^{n} c_{j} Y_{t-1}+u_{t}
$$

$$
Y_{t}=a+\sum_{i=1}^{r} \beta_{i} Y_{t-1}+\sum_{i=1}^{s} r_{j} X_{t-j}+v_{t}
$$

em que $a$ e $\alpha$ são constantes, $u_{t}$ e $v_{t}$ são erros aleatórios de média zero e variância constante. Nesse modelo, supõe-se que as séries $X_{t}$ e $Y_{t}$ têm covariâncias estacionárias.

Bartels e Colombo (2015) utilizaram testes de causalidade para analisarem a interdependência entre a produção industrial e a atividade de transporte rodoviário de carga no Brasil, enquanto Kruger e Petri (2013) analisaram a relação de causalidade entre as medidas de desempenho EVA, LPA, ROE, ROA, VM com o MVA das empresas listadas na BM\&F Bovespa, visando identificar a eficiência da utilização dessas medidas como métricas para a análise e acompanhamento do desempenho dos negócios de determinadas empresas pesquisadas. Tang (2011) analisou a relação dinâmica no sistema de saúde da Malásia por meio da causalidade de Granger, enquanto Galdi e Lopes (2008) analisaram se há relação de longo prazo e causalidade entre o lucro contábil e o preço das ações de empresas da América Latina. Basso e Pace (2003) fizeram uma análise crítica da direção causal no Balanced Scored Card, utilizando os preceitos da causalidade de Granger.

\section{Modelos de análise}

Para analisar a relação causal entre confiança nos relacionamentos verticais e horizontais do setor moveleiro, foi avaliada a existência da correlação entre as variáveis e, posteriormente, a da causalidade. Foram definidos três modelos de análise, demonstrados no Quadro 1.

\section{Quadro 1. Modelos utilizados na pesquisa}

\begin{tabular}{l|l}
\hline Modelo 1 & $\begin{array}{l}\text { Confiança nas relações verticais: } \\
\text { Confiança nos clientes } \leftrightarrow \text { Confiança nos fornecedores }\end{array}$ \\
\hline Modelo 2 & $\begin{array}{l}\text { Confiança nas relações horizontais: } \\
\text { Benevolência nos polos } \leftrightarrow \text { Comprometimento nos polos }\end{array}$ \\
\hline Modelo 3 & $\begin{array}{l}\text { Confiança nas relações verticais e horizontais: } \\
\text { Confiança fornecedores } \leftrightarrow \text { Benevolência nos polos } \\
\text { Confiança fornecedores } \leftrightarrow \text { Benevolência nos polos } \\
\text { Confiança clientes } \leftrightarrow \text { Comprometimento nos polos }\end{array}$ \\
\hline
\end{tabular}

No Modelo 1 visto na Figura 1, buscou-se analisar o relacionamento vertical: se a confiança nos clientes causa a confiança nos fornecedores, e também se a confiança nos fornecedores causa a confiança nos clientes. A intenção foi avaliar se há colaboração no relacionamento entre as empresas do polo moveleiro com seus fornecedores e clientes a partir da dimensão confiança. 
Figura 1. Confiança nos relacionamentos verticais

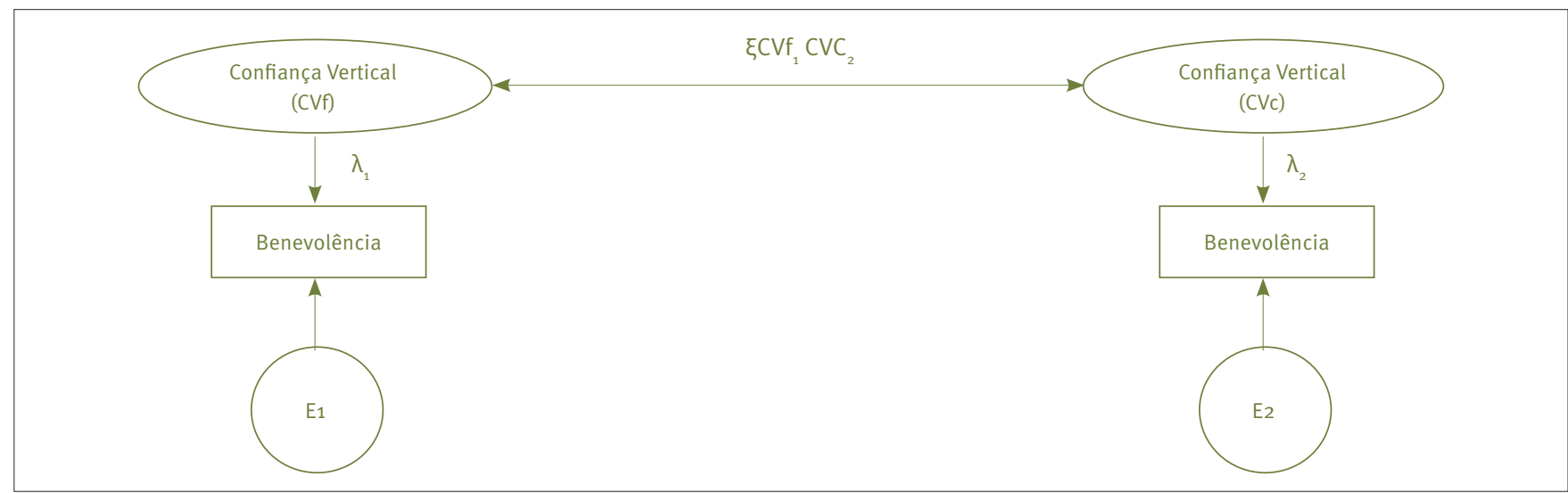

No Modelo 2 apresentado na Figura 2, o foco foi a análise do relacionamento horizontal: se a benevolência nos polos causa o comprometimento nos polos, e também se o comprometimento nos polos causa a benevolência nos polos. Nessa análise, o objetivo foi avaliar se há colaboração no relacionamento entre as empresas concorrentes do polo moveleiro, cruzando a variável confiança com a variável comprometimento.

Figura 2. Confiança nos relacionamentos horizontais

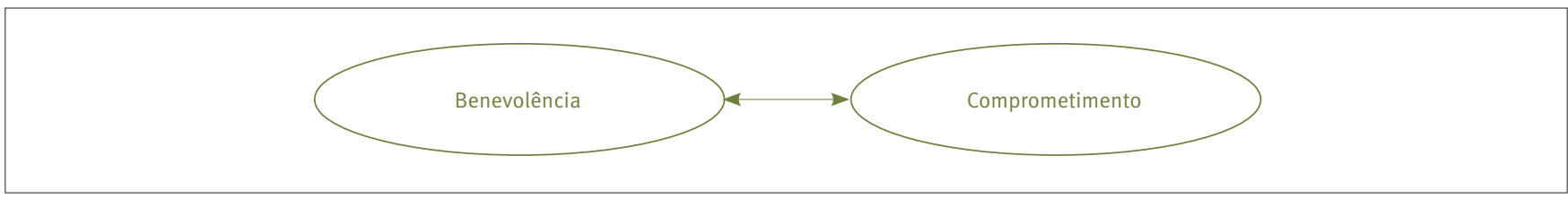

Na sequência, foi analisada a relação de causalidade entre os relacionamentos verticais e os relacionamentos horizontais. A Figura 3 demonstra essa relação. Logo, o Modelo 3 se desmembra em algumas análises: se a confiança nos fornecedores provoca a benevolência nos polos, se a confiança nos clientes causa a benevolência nos polos, se a confiança nos fornecedores causa o comprometimento nos polos, e, por fim, se a confiança nos clientes causa o comprometimento nos polos. A intenção dessas análises foi avaliar se há relação de causalidade entre os relacionamentos verticais e horizontais. Isso significa dizer que foi avaliado se o relacionamento vertical, aqui tratado como confiança nos fornecedores e confiança nos clientes, causou a colaboração no relacionamento horizontal, tratado como benevolência nos polos e comprometimento nos polos.

Figura 3. Confiança nos relacionamentos verticais e horizontais

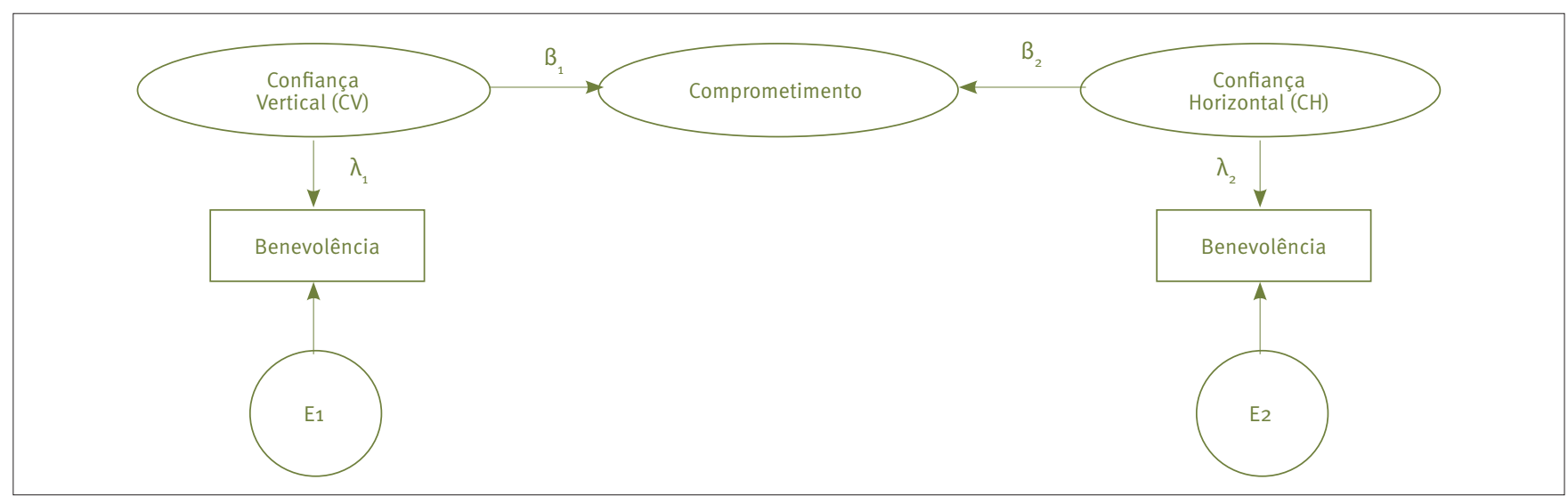


A análise dos dados foi realizada com o auxílio do software estatístico R, considerando duas dimensões: relacionamento vertical e relacionamento horizontal, e duas variáveis por modelo.

\section{RESULTADOS E IMPLICAÇÕES}

A análise de correlação para a confiança nos relacionamentos verticais e horizontais está apresentada na Tabela 1. Observa-se que todas as dimensões possuíram correlações positivas entre as duplas de variáveis e todas foram significativas ao nível de $10 \%$ $(P$ - valor > 0,10). A confiança entre fornecedores e clientes possui correlação linear de 35,30\%, e a benevolência dos polos está correlacionada em $58,71 \%$ com o comprometimento dos polos.

Tabela 1. Correlação e teste de significância para os relacionamentos verticais e horizontais

\begin{tabular}{c|c|c|c|c|c}
\hline Relacionamento & Variável 1 & Variável 2 & Correlação & P valor - T test & Conclusão \\
\hline Vertical & Confiança fornecedores & Confiança clientes & $35,30 \%$ & 0,0020 & Correlação significante \\
\hline Horizontal & Polo benevolência & Polo comprometimento & $58,71 \%$ & 0,0000 & Correlação significante \\
\hline
\end{tabular}

Como o fato da correlação significativa não é suficiente para definir a causalidade entre as variáveis, foi feita uma análise complementar para verificar essa relação. Assim, para verificar se existe alguma relação causal entre as variáveis, utilizou-se o teste de causalidade de Granger, com duas defasagens da variável regressora de teste. As defasagens foram definidas a partir do Critério de Informação de Akaike (AIC), indicado para amostras com mais de 40 observações.

Conforme informações descritas na Tabela 2, ao nível de $10 \%$ de significância, observa-se que a benevolência nos polos causa o comprometimento destes, sendo essa a única relação causal verificada. Pode-se afirmar que a confiança no fornecedor não implica confiança no cliente e vice-versa, e o comprometimento das empresas do polo não implica a benevolência.

Tabela 2. Causalidade de Granger para os relacionamentos verticais e horizontais

\begin{tabular}{c|c|c|c|c}
\hline \multirow{2}{*}{ Relacionamento } & Variável 1 & Variável 2 & $\begin{array}{c}\text { Causalidade de Granger } \\
\text { (P valor) }\end{array}$ & Conclusão \\
\hline \multirow{2}{*}{ Vertical } & Confiança fornecedores & Confiança clientes & 0,176 & Não há causalidade \\
\cline { 2 - 5 } & Confiança clientes & Confiança fornecedores & 0,337 & Não há causalidade \\
\hline \multirow{2}{*}{ Horizontal } & Benevolência polo & Comprometimento polo & 0,055 & Há causalidade \\
\cline { 2 - 6 } & Comprometimento polo & Benevolência polo & 0,623 & Não há causalidade \\
\hline
\end{tabular}

A Tabela 3 apresenta a correlação entre os relacionamentos vertical e horizontal. A correlação entre confiança por parte de clientes e a benevolência dos polos se mostrou significativa ao nível de confiança de 10\%. Por sua vez, a relação entre a confiança dos fornecedores e a benevolência dos polos mostrou a não existência de correlação significativa.

Tabela 3. Correlação e teste de significância entre os relacionamentos verticais e horizontais

\begin{tabular}{|c|c|c|c|c|}
\hline Confiança fornecedores & Benevolência polo & $18,65 \%$ & 0,1142 & Correlação não significante \\
\hline Confiança fornecedores & \multirow{2}{*}{ Comprometimento polo } & $11,54 \%$ & 0,3306 & \multirow{2}{*}{ Correlações não significantes } \\
\hline Confiança clientes & & $14,72 \%$ & 0,2108 & \\
\hline
\end{tabular}


Analisou-se, ainda, a relação entre confiança nos fornecedores e confiança nos clientes com o comprometimento no polo. Os resultados encontrados mostraram correlações abaixo de $15 \%$ e não significativas. Em relação aos testes de causalidade, nenhum se mostrou significativo.

\section{Implicações}

Foi constatada a ocorrência de confiança, de maneira significativa, nos relacionamentos verticais, porém a ocorrência é concentrada nos fornecedores ou nos clientes. Portanto, colaborar com fornecedores e com clientes são decisões independentes, pois não há relação de causalidade entre elas. Pela perspectiva relacional, infere-se que as empresas parecem identificar fornecedores ou clientes como fontes potenciais de adição de valor, mas não a chamada rede de suprimentos. Sugere-se, dessa forma, uma conduta orientada comercialmente, tendo em mente os resultados unilaterais da relação. Dessa forma, o potencial de captura de vantagem competitiva oriunda do relacionamento (Dyer \& Singh, 1998) não é aproveitada integralmente, assim como a ampliação dos seus recursos e competências internas (Lavie, 2006). Ademais, conforme Rossoni et al. (2014), os mecanismos de imersão relacional e estrutural, quando interligados, é que proporcionarão o alcance de benefícios adicionais para as organizações, mais do que se fossem usados isoladamente.

A organização desses polos moveleiros em clusters pode ser entendida como um fator facilitador para a colaboração, já que o fato de as empresas estarem aglomeradas regionalmente favorece a construção dos vínculos verticais e horizontais. A maior proximidade com clientes proporciona melhores condições para aprimoramento da qualidade do produto, bem como permite capturar as avaliações dos clientes para melhorar continuamente os produtos entregues (Cheung, Myers, \& Mentzer, 2010). Já a proximidade com fornecedores oportuniza ganhos em inovação e custos. Contudo, é importante ressaltar que o comportamento colaborativo precisa ser efetivamente materializado por meio da ação conjunta das empresas aglomeradas geograficamente (Galinari et al., 2013).

Por outro lado, apesar da correlação significativa nos relacionamentos verticais, não é possível inferir se as empresas do polo moveleiro confiam mais em seus clientes ou em seus fornecedores. Contudo, Deboçã e Martins (2014) estudaram questões de relacionamentos nos polos moveleiros de Mirassol e Ubá e constataram que, no relacionamento vertical, as empresas moveleiras destacam os clientes com maior importância relativa quando comparados aos fornecedores.
Em parte, pode-se contextualizar o comportamento encontrado pelo fato de a indústria moveleira, que é composta em sua maioria por micro, pequenas e médias empresas, possuir uma característica, um pouco contraditória, de verticalização dos processos produtivos (Galinari et al., 2013). Segundo Silveira, Martins, Lopes, e Alves (2013), cerca de $30 \%$ dos custos totais dos produtos referem-se a custos com processos terceirizados. Nesse sentido, apesar de haver confiança nos relacionamentos verticais, tais empresas não se beneficiam plenamente de sua localização geográfica, tampouco do potencial desses relacionamentos, já que existe uma tendência de não promover a terceirização de muitos dos processos produtivos.

Essa importância relativa dos clientes pode sugerir que as indústrias moveleiras tenham uma orientação para o mercado. Os resultados de Tseng e Liao (2013) indicam que orientações para o mercado e ferramentas da tecnologia de informação influenciam positivamente a integração da rede de suprimentos. 0 estudo afirma que as empresas que possuem essas características integram mais facilmente as informações de mercado com seus parceiros e clientes. Além disso, a integração da rede de suprimentos e a orientação para o mercado têm um efeito positivo sobre o desempenho da empresa.

É preciso, porém, também avaliar com mais acurácia e profundidade até que ponto esse viés para o mercado não é um sintoma de dependência em relação aos compradores, que, no caso, são majoritariamente grandes cadeias do varejo (Rossoni et al., 2014) e têm volume de compra que também orienta a produção e a lucratividade do negócio. Segundo Deboçã e Martins (2014), esse é um fator decisivo.

Comparando a correlação entre os elos, verifica-se que o relacionamento horizontal é mais correlacionado $(58,71 \%)$ que o relacionamento vertical $(35,30 \%)$. Todavia, como as variáveis utilizadas para análise de correlação são diferentes, esse comparativo não deve ser feito de maneira absoluta, sendo refém das variáveis incorporadas. Entende-se que a confiança no elo horizontal seja mais forte, contudo não é possível generalizar, porque, ao mudar as variáveis incorporadas, não há garantias de obtenção dos mesmos resultados. Como exemplo da impossibilidade de generalização, Galinari et al. (2013) relataram que, entre as empresas que praticam atividades de cooperação, o relacionamento de confiança com fornecedores é mais comum que o relacionamento de confiança com os concorrentes.

A correlação nos relacionamentos horizontais medida pelas variáveis benevolência nos polos e comprometimento nos polos também se apresentou significativa. Contudo, o teste de causalidade demonstrou que, nos polos, a benevolência causa o comprometimento, e que o inverso não é verdadeiro. 
Esse resultado está alinhado aos preceitos de Morgan e Hunt (1994), que definem o comprometimento e a confiança como fatores centrais para o sucesso do relacionamento. Portanto, quando ambos estão presentes no relacionamento interorganizacional, produzem resultados que promovem a eficiência, a produtividade e a eficácia, e inibem ações oportunistas pelas partes envolvidas.

Assim, a confiança causa o comprometimento, e ambos estão presentes nos relacionamentos horizontais. Para Zhao, Huo, Flynn, e Yeung (2008), a confiança é o coração do comprometimento. Entretanto, a confiança presente nos relacionamentos verticais não é suficiente para conduzir o relacionamento ao comprometimento nas relações horizontais. Isso significa dizer que, ao se comprometerem em um relacionamento horizontal, os envolvidos entendem que a atuação em conjunto fortalecerá o negócio e suas demandas político-institucionais.

Adicionando a ótica relacional, percebe-se que a confiança é a base para os relacionamentos colaborativos e que a sua prática constrói o capital social da empresa. Assim, ampliar o capital social nos relacionamentos horizontais proporciona melhores acessos às informações, poder e solidariedade (Lesser, 2000; Nahapiet, 2008), criando ou expandindo uma rede de relações sociais.

Raue e Wieland (2014), ao analisarem o relacionamento horizontal em operadores de serviços logísticos (OSL), perceberam que esse relacionamento tem ganho importância e que grande parte dos OSLs está engajada em uma ou múltiplas formas de cooperação com seus concorrentes. Por meio da cooperação com potenciais OSLs, as partes que cooperam são capazes de se beneficiarem em dois campos: o acesso a recursos tangíveis e a contribuição direta para a performance.

Assim, da mesma forma que a cooperação em relacionamentos horizontais pode trazer ganhos significativos para OSL, também pode beneficiar as empresas moveleiras. A partir dessa cooperação, é possível buscar conjuntamente melhores recursos, preços e oportunidades que podem contribuir direta ou indiretamente para o desempenho da empresa. Os resultados dos relacionamentos horizontais tendem a se convergir na redução de custos de transação, no desenvolvimento de estratégias mercadológicas, na aquisição de insumos, no compartilhamento de instalações, máquinas, equipamentos ou ferramentas de uso comum, nas informações sobre mercado e no desenvolvimento de novos produtos ou processos. Como exemplo de redução no custo de transação, a indústria moveleira pode compartilhar fretes para o suprimento das indústrias ou até mesmo a inserção de uma central de compras que una as necessidades das empresas e negocie por elas.

\section{CONCLUSÕES}

Este estudo pretendeu obter evidências da propensão à colaboração das empresas em seus relacionamentos interorganizacionais. A dimensão confiança foi utilizada metodologicamente para captar esse comportamento, tanto no âmbito dos relacionamentos horizontais quanto no âmbito dos relacionamentos verticais. Dessa forma, entende-se que o artigo contribuiu para a compreensão mais ampla do comportamento de organizações que buscam captar valor nos relacionamentos.

Ficou caracterizada a presença de confiança nos relacionamentos verticais e horizontais. Porém, as empresas industriais demonstraram-se mais propensas a colaborar com clientes, quando também se constatou maior benevolência para o comprometimento no polo. Mas não houve confirmação de presença simultânea de confiança nos relacionamentos com clientes e fornecedores. Assim, a confiança no fornecedor não implica a confiança no cliente, e vice-versa. Esses resultados podem sugerir que a confiança está pautada em ações isoladas, e essts podem ser entendidas como ações praticadas por interesses comerciais. Pela perspectiva relacional, as organizações pesquisadas indicaram não se relacionarem sob a perspectiva da rede de suprimentos.

No que diz respeito aos relacionamentos horizontais, depreende-se que a confiança entre os pares é mais significativa. Cabe lembrar que o estudo aborda clusters produtivos, logo colocam competidores próximos geograficamente e que mantêm vínculos de relacionamentos sociais. Tais vínculos podem atenuar o ambiente da concorrência e capturar benefícios do capital social e da interação em rede. Ademais, é um conjunto de empresas de pequeno porte, e isso favorece a busca pela união em torno de demandas e ações que possam ter externalidades para todos.

Isso posto, nota-se que a confiança é intencional: em dada situação, as empresas aproximam-se de clientes ou fornecedores com a finalidade de capturar benefícios comerciais, e, noutra situação, aproximam-se de seus concorrentes em busca de proteção. Logo, as organizações estudadas indicaram utilizar confiança nos relacionamentos como um elemento da estratégia comercial e longevidade dos negócios, mais do que uma propensão a atitudes colaborativas.

Ao evidenciar a relação horizontal como mais bem dotada de confiança que a relação a vertical, este estudo instiga trabalhos futuros para o aprofundamento das razões que levam a compreender por que se confia mais em concorrentes que nos parceiros de negócios. Sugerem-se, então, estudos que aprofundem a relação entre a geografia econômica e a confiança nos relacionamentos verticais e horizontais em cluster de empresas. 
Outrossim, estudos que pudessem relacionar a ocorrência do construto confiança e a cultura organizacional contribuiriam para uma melhor compreensão do comportamento dessas empresas que parecem "forjar" uma relação próxima, abrindo chances para serem vítimas de oportunismo por parte de seus parceiros, o que a literatura tem chamado de dark side da colaboração. Nesse caso, maiores níveis de confiança não redundarão em maiores benefícios ou maiores níveis de desempenho da organização, se isolados de mecanismos de governança. Mas quais deles seriam mais eficazes e eficientes, e em quais ambientes empresariais?

\section{REFERÊNCIAS}

Adler, P., \& Kwon, S. (2000). Social capital: The good, the bad, and the ugly. In L. E. Lesser (Org.), Knowledge and social capital: Foundations and applications (pp. 89-115). Woburn: USA

Bachmann, R., \& Zaheer, A. (2008). Trust in inter-organizational relations. In S. Cropper, M. Ebers, C. Huxhan, \& P. Smith Ring et al. (Orgs.), Oxford handbook of inter-organizational relations (pp. 533554). Oxford: Oxford University Press, United States of America.

Badea, A., Prostean, G., Goncalves, G., \& Allaoui, H. (2014). Assessing risk factors in collaborative supply chain with the analytic hierarchy process (AHP). Procedia: Social and Behavioral Sciences, (124), 114123. doi: 10.1016/j.sbspro.2014.02.467

Ballou, R. H., Gilbert, S. M., \& Mukherjee, A. (2000). New managerial challenges from supply chain opportunities. Industrial Marketing Management, 29, 7-18.

Bartels, M., \& Colombo, J. A. (2015). Interdependência entre a indústria de transformação e os serviços de transporte: Evidências para o Rio Grande do Sul e para o Brasil. Ensaios FEE, 36(2), 285-322.

Basso, L. F. C., \& Pace, E. S. U. (2003). Uma análise crítica da direção da causalidade no Balanced Scorecard. RAE-eletrônica, 2(1). Recuperado de http://www.scielo.br/pdf/raeel/v2n1/v2n1a11.pdf

Braziots, C., \& Tannock, J. (2011). Building the extended enterprise: Key collaboration factors. The International Journal of Logistics, $22(3)$, 349-372. doi: 10.1108/09574091111181363

Burt, R. S. (2001). Structural holes versus network closure as social capital. In N. Lin, K. Cook, \& R. S. Burt (Orgs.), Social capital: Theory and research (pp. 31-56). New York, USA: Aldine de Gruyter.

Cantù, C. (2010). Exploring the role of spatial relationships to transform knowledge in a business idea: Beyond a geographic proximity. Industrial Marketing Management, 39(6), 887-897. doi: 10.1016/j. indmarman.2010.06.008

Cheung, M. S., Myers, M. B., \& Mentzer, J. T. (2010). Does relationship learning lead to relationship value? A cross-national supply chain investigation. Journal of Operations Management, 28(6), 472-487. doi: $10.1016 / j$ j.jom.2010.01.003

Daugherty, P. (2011). Review of logistics and supply chain relationship literature and suggested research agenda. International Journal of Physical Distribution \& Logistical Management, 41(10), 16-31. doi: 10.1108/09600031111101402
Deboçã, L. P., \& Martins, R. S. (2014). Relacionamentos interorganizacionais em empresas de pequeno porte e sua inserção em cadeias de suprimentos. Revista Administração UFSM, 8(4), 706-724. doi: 10.5902/1983465912409

Dyer, J. H., \& Chu, W. (2003) The role of trustworthiness in reducing transaction costs and improving performance: Empirical evidence from the United States, Japan, and Korea. Organization Science, $14(1), 57-68$.

Dyer, J. H., \& Singh, H. (1998). The relational view: Cooperative strategy and sources of interorganizational competitive advantage. The Academy of Management Review, 23(4), 660-679.

Galdi, F. C., \& Lopes, A. B. (2008). Relação de longo prazo e causalidade entre o lucro contábil e o preço das ações: Evidências do mercado latino-americano. RAUSP-Revista de Administração da Universidade de São Paulo, 43(2), 186-201.

Galinari, R., Teixeira, J. R., Junior, \& Morgado, R. R. (2013). A competitividade da indústria de móveis do Brasil: Situação atual e perspectivas. BNDES Setorial, (37), 227-272.

Granovetter, M. (2007). Ação econômica e estrutura social: 0 problema da imersão. RAE-eletrônica, 6(1), Art. 9. Recuperado de http://www. scielo.br/pdf/raeel/v6n1/ao6v6n1.pdf

Halinen, A., \& Tornroos, J. (1998). The role of embeddedness in the evolution of business networks. Scandinavian Journal of Management, 14(3), 187-205. doi: 10.1016/S0956-5221(98)80009-2

Kruger, S. D., \& Petri, S. M. (2013). Análise comparativa da causalidade de medidas de desempenho das empresas da BM\&FBovespa no período de 2000 a 2010. Revista de Contabilidade do Mestrado em Ciências Contábeis da UERJ, 18(1), 81-103.

Kumar, g., Banerjee, R. N., Meena, P. L., \& Anguly, K. (2016). Collaborative culture and relationship strength roles in collaborative relationships: A supply chain perspective. Journal of Business \& Industrial Marketing, 31(5), 587-599. doi: 10.1108/JBIM-12-2014-0254

Lado, A. A., Dant, R. R., \& Tekleab, A. G. (2008). Trust-opportunism paradox, relationalism, and performance in interfirm relationships: Evidence from the retail industry. Strategic Management Journal, 29(4), 401-423. doi: 10.1002/smj.667

Lambert, D. M., \& Einz, M. G. (2016). Issues in supply chain management: Progress and potential. Industrial Marketing Management, 62, 1-16. doi: 10.1016/j.indmarman.2016.12.002

Lavie, D. (2006). The competitive advantage of interconnected firms: An extension of the resource-based view. Academy of Management Review, 31(3), 638-658.

Lesser, L. E. (2000). Leveraging social capital in organizations. In L. E. Lesser (Org.), Knowledge and social capital: Foundations and applications (pp. 3-16). Woburn: Butterworth-Heinemann, United States of America.

Lin, N. (2001). Social capital: A theory of social structure and action. Cambridge: Cambridge University Press United States of America.

Maddala, G. S. (1992). Introduction to econometrics (2nd ed.). New York, USA: MacMillan.

Mason, R., Lalwani, C., \& Boughton, R. (2007). Combining vertical and horizontal collaboration for transport optimisation. Supply Chain Management: An International Journal, 12(3), 187-199. doi: 10.1108/13598540710742509

Matell, M. S., \& Jacoby, J. (1972). Is there an optimal number of alternatives for Likertscale items? Effects of testing time and scale properties. Journal of Applied Psychology, 56(6) 506-509. 
Mayer, R. C., Davis, J. H., \& Schoorman, F. D. (1995). An integrative model of organizational trust. Academy of Management Review, 20(3), 709734 .

Morgan, R. M., \& Hunt, S. D. (1994). The commitment-trust theory of relationship marketing. Journal of Marketing, 58(3), 20-38. doi: $10.2307 / 1252308$

Nahapiet, J. (2008). The role of social capital in inter-organizational relationships. In S. Cropper M. Ebers, C. Huxhan, \& P. Smith Ring et al. (Orgs.), The Oxford handbook of inter-organizational relations ( $\mathrm{pp}$. 580-606). Oxford: Oxford University Press, United States of America.

Nahapiet, J., \& Ghoshal, S. (1998). Social capital, intellectual capital, and the organizational advantage. Academy of Management, 23(2), 242-266.

Nicholson, J., Tsagdis, D., \& Brennan, R. (2013). The structuration of relational space: Implications for firm and regional competitiveness. Industrial Marketing Management, 42, 372-381. doi: 10.1016/j. indmarman.2013.02.013

Raue, J. S., \& Wieland, A. (2014). The interplay of different types of governance in horizontal cooperations: A view on logistics service providers. The International Journal of Logistics Management, 26(2), 401-423. doi: 10.1108/IJLM-08-2012-0083

Redondo, Y. P., \& Fierro, J. J. C. (2007). Importance of company size in long-term orientation of supply function: An empirical research. Journal of Business and Industrial Marketing, 22(4), 236-248. doi: $10.1108 / 08858620710754504$

Rossoni, L., Martins, G. S., Martins, R. S., \& Silveira, R. I. M. (2014). Imersão social na cadeia de suprimentos e seu efeito paradoxal no desempenho operacional. RAE-Revista de Administração de Empresas, 54(4), 429-444. doi: 10.1590/So034-759020140408
Silveira, R. I., Martins, R. S., Lopes, A. L. M., \& Alves, A. F. (2013). Antecedentes da eficiência produtiva na manufatura: Experiências do setor moveleiro brasileiro. Revista de Ciências da Administração, 15(37), 154-169. doi: 10.5007/2175-8077.2013V15n37p154

Simatupang, T. M., \& Sridharan, R. (2002). The collaborative supply chain. International Journal of Logistics Management, 13(1), 15-30. doi: 10.1108/09574090210806333

Slack, N., Chambers, S., \& Johnston, R. (2009). Administração da produção. São Paulo, SP: Atlas.

Tang, C. F. (2011). Multivariate granger causality and the dynamic relationship between health care spending, income and relative price of health care in Malaysia. Hitotsubashi Journal of Economics, 52(2) 199-214. Retrieved from http://www.jstor.org/stable/43296255

Tseng, P. H., \& Liao, C. H. (2013). Supply chain integration, information technology, market orientation and firm performance in container shipping firms. The International Journal of Logistics Management, 26(1) 82-106. doi: 10.1108/IJLM-09-2012-0088

Zaheer, A., \& Harris, J. (2006). Interorganizational trust. In O. Shenkar, \& J. Reuer (Orgs.), Handbook of strategic alliance (pp. 169-197) Thousand Oaks, USA: Sage.

Zajac, E. J., \& Olsen, C. P. (1993). From transaction cost to transactional value analysis: Implications for the study of the interorganizational strategies. Journal of Management Studies, 30(1), 131-145. doi: 10.1111/j.1467-6486.1993.tbo0298.x

Zhao, X., Huo, B., Flynn, B. B., \& Yeung, J. H. Y. (2008). The impact of power and relationship commitment on the integration between manufacturers and customers in a supply chain. Journal of Operations Management, (26), 368-388. doi: 10.1016/j.jom.2007.08.002 